Original Article

\title{
The Financial Impact on Reimbursement of Moderately Hypofractionated Postoperative Radiation Therapy for Breast Cancer: An International Consortium Report
}

\author{
G.N. Marta*, D. Ramiah $\dagger$, O. Kaidar-Person $\ddagger$, A. Kirby $\S \uparrow$, C. Coles $\|$, R. Jagsi ${ }^{* *}$, T. Hijal $\dagger \dagger$, \\ G. Sancho + , Y. Zissiadis $\S \S$, J.-P. Pignol $\llbracket \uparrow$, A.Y. Ho |||| , S.H.-C. Cheng ${ }^{* * *}$,

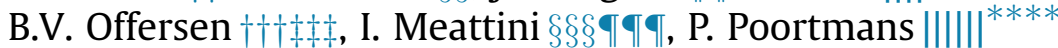 \\ * Department of Radiation Oncology, Hospital Sírio-Libanês, São Paulo, Brazil \\ ${ }^{\dagger}$ Department of Radiation Oncology, Donald Gordon Medical Centre, Johannesburg, South Africa \\ ${ }^{\ddagger}$ Breast Cancer Radiation Unit, Radiation Oncology Institute, Sheba Medical Center, Ramat Gan, Israel \\ ${ }^{\S}$ Department of Radiotherapy, Royal Marsden NHS Foundation Trust, London, UK \\ IInstitute of Cancer Research, London, UK \\ "Department of Oncology, University of Cambridge, Cambridge, UK \\ ** Department of Radiation Oncology, University of Michigan, Ann Arbor, MI, USA \\ ${ }^{\dagger \dagger}$ Division of Radiation Oncology, McGill University Health Centre, Montréal, Quebec, Canada \\ ${ }_{\ddagger}^{\ddagger}$ Department of Radiation Oncology, Hospital de la Santa Creu i Sant Pau, Barcelona, Spain \\ $\S \S$ Department of Radiation Oncology, Genesis Cancer Care, Wembley, WA, Australia \\ ฯ Department of Radiation Oncology, Dalhousie University, Halifax, Nova Scotia, Canada \\ IIII Department of Radiation Oncology, Massachusetts General Hospital, Boston, MA, USA \\ *** Department of Radiation Oncology, Koo Foundation Sun Yat-Sen Cancer Center, Taipei, Taiwan \\ ${ }^{\dagger \dagger \dagger}$ Department of Oncology, Aarhus University Hospital, Aarhus, Denmark \\ ${ }_{\ddagger \ddagger}^{\ddagger \ddagger}$ Department of Experimental Clinical Oncology, Aarhus University Hospital, Aarhus, Denmark \\ ${ }_{\S \S}$ Radiation Oncology Unit, Oncology Department, Azienda Ospedaliero Universitaria Careggi, Florence, Italy \\ 9ब Department of Biomedical, Experimental, and Clinical Sciences "M. Serio", University of Florence, Florence, Italy \\ IIIIII Department of Radiation Oncology, Iridium Kankernetwerk, Wilrijk-Antwerp, Belgium \\ **** University of Antwerp, Faculty of Medicine and Health Sciences, Wilrijk-Antwerp, Belgium
}

Received 21 August 2020; received in revised form 6 November 2020; accepted 8 December 2020

\begin{abstract}
Aims: Moderately hypofractionated breast irradiation has been evaluated in several prospective studies, resulting in wide acceptance of shorter treatment protocols for postoperative breast irradiation. Reimbursement for radiation therapy varies between private and public systems and between countries, impacting variably financial considerations in the use of hypofractionation. The aim of this study was to evaluate the financial impact of moderately hypofractionated breast irradiation by reimbursement system in different countries.

Materials and methods: The study was designed by an international group of radiation oncologists. A web-questionnaire was distributed to representatives from each country. The participants were asked to involve the financial consultant at their institution.

Results: Data from 13 countries from all populated continents were collected (Europe: Denmark, France, Italy, the Netherlands, Spain, UK; North America: Canada, USA; South America: Brazil; Africa: South Africa; Oceania: Australia; Asia: Israel, Taiwan). Clinicians and/or departments in most of the countries surveyed (77\%) receive remuneration based on the number of fractions delivered to the patient. The financial loss per patient estimated resulting from applying moderately hypofractionated breast irradiation instead of conventional fractionation ranged from 5-10\% to 30-40\%, depending on the healthcare provider. Conclusion: Although a generalised adoption of moderately hypofractionated breast irradiation would allow for a considerable reduction in social and economic burden, the financial loss for the healthcare providers induced by fee-for-service remuneration may be a factor in the slow uptake of these regimens. Therefore,
\end{abstract}

Author for correspondence: G.N. Marta, Department of Radiation Oncology, Hospital Sírio-Libanês, Rua Dona Adma Jafet 91, Sao Paulo-SP 01308-050, Brazil. Tel: +55-11-33945367.

E-mail address: gustavonmarta@gmail.com (G.N. Marta). 
fee-for-service reimbursement may not be preferable for radiation oncology. We propose that an alternative system of remuneration, such as bundled payments based on stage and diagnosis, may provide more value for all stakeholders.

(c) 2020 The Royal College of Radiologists. Published by Elsevier Ltd. All rights reserved.

Key words: Breast cancer; health economics; hypofractionation; radiation therapy; reimbursement

\section{Introduction}

The burden of cancer is increasing as a result of several factors, including an aging population. Even though there is international variation in breast cancer incidence and mortality between countries, breast cancer remains the most frequent cancer and the most common cause of cancer death in women internationally [1].

Breast cancer accounts for the highest healthcare expenses in the European Union [2]. Expenses are mostly from breast cancer medication costs. However, screening programmes, diagnostic procedures, other treatments modalities and other care costs, together with the productivity lost (e.g. time lost to the patient from work in order to receive treatments), significantly contribute to the economic burden posed by breast cancer [3].

In the curative setting, postoperative radiation therapy for breast cancer has been shown in systematic reviews and meta-analyses of prospective trials to reduce the locoregional relapse rate and to increase survival rates $[4,5]$. Previously, postoperative breast radiation therapy was given over a period of 5-6 weeks (total radiation therapy dose of $50-50.4 \mathrm{~Gy}$ in $1.8-2$ Gy per fraction). In recent decades, moderately hypofractionated breast radiation therapy regimens have used slightly larger daily radiation therapy fraction sizes (e.g. 2.5-3.0 Gy), with reduced total dose and over a shorter period of time (e.g. 3 weeks), designed to achieving similar clinical outcomes to conventionally fractionated regimens [6,7]. Long-term follow-up in large randomised phase III trials supported the safety and efficacy of the hypofractionation protocols compared with 1.8-2 Gy fractionations [8,9]. Adoption of hypofractionation for breast cancer can reduce the burden of treatment, with significant implications for health economics and services. Shorter treatment protocols reduce the case load at radiation therapy units and of the treating teams, thus freeing up resources for more patients. It can also decrease indirect costs associated with patient's daily travelling and work disruptions (loss of productivity) and reduce other unaccounted for treatment-related costs [10].

Despite there being high-level evidence to support the use of hypofractionation-based radiation therapy for breast cancer, together with significant financial benefits for health economies, it has not been adopted in many countries [11]. This might be explained because the adoption of shorter treatment regimens in the proportionally important breast cancer patient population substantially reduces radiation therapy activity, which could result in a financial loss depending on the reimbursement system. On the other hand, the adoption of shorter treatment regimens may have a significant beneficial impact on health economics by creating space for other treatments and decreasing waiting times.

The aim of this study was to calculate the financial impact of adopting moderately hypofractionated breast radiation therapy in different reimbursement systems and to provide data and proposals on how to overcome financial barriers to adopting hypofractionated radiation therapy for breast cancer patients.

\section{Materials and Methods}

This study was designed by an international consortium of radiation oncology experts. Data regarding costs and reimbursement issues related to moderately hypofractionated postoperative radiation therapy for breast cancer patients were collected from countries in all continents. A summary of these data was distributed to all experts in breast cancer care to facilitate a discussion about the use of hypofractionation for different curative settings of postoperative breast radiation. Thereafter, a web-questionnaire was designed to collect specific and relevant data to assess current reimbursement systems per country. This instrument included several variables that could be related to reimbursement calculation. If a variable was not applicable for the reimbursement calculation, it was described as 'not applicable'.

Data concerning reimbursement systems as applied in the contributors' countries were collected. Depending on the organisation of healthcare per country, the information is in general valid for a healthcare region or an entire country.

The reimbursement systems and the influence of hypofractionation-based radiation schedules on revenue were evaluated from both public and private (when applicable) practice perspectives. Basically, the two mainstream reimbursement systems are 'fee-for-service' (most systems are based on payment per fraction of radiation therapy) and the 'global (lump sum/fixed fee)' method. Therefore, we divided the observed worldwide variance of reimbursement systems into two groups: separate fees per activity (fee-forservice) or lumpsum for the entire treatment (fixed fee).

In the case of per fee-for-service, information about reimbursement fees was collected for two-dimensional (radiation therapy) treatment planning, three-dimensional conformal radiation therapy planning, intensity-modulated radiation therapy (IMRT) planning, per fractionation, per treatment week and for on-treatment physician visits. Information was provided by the authors of this study in collaboration with their local institutional financial departments or national policies. As the relative value of euro and dollar varies by only $10 \%$, we did not recalculate into one single currency and assume this as unity. 


\section{Results}

In total, data from 13 countries were collected (Europe: Denmark, France, Italy, the Netherlands, Spain, UK; North America: Canada, USA; South America: Brazil; Africa: South Africa; Oceania: Australia; Asia: Israel, Taiwan). Within Canada and Italy, where healthcare is managed on a provincial level, the provinces of Nova Scotia and Quebec, and Tuscany and Lombardy reported data separately. The number of fractions influenced reimbursement in most countries (77\%). The corresponding revenue loss generated by the reduction in per-patient income from applying a hypofractionation-based schedule ranged from $5-10 \%$ to
$30-40 \%$ (Table 1 ). When a revenue loss occurred, most countries (60\%) reported a loss of $30-40 \%$ (Figure 1).

A variety of reimbursement systems exist in the evaluated countries. From the public sector perspective, in most countries (Australia, Canada - Quebec, Israel, Italy, Spain, Taiwan, UK and USA), reimbursement differs based on treatment planning technique; only three countries do not differentiate between IMRT planning and threedimensional conformal radiation therapy planning (Denmark, Canada - Nova Scotia and France). Similarly, for all countries that have private practice, IMRT planning is related to higher reimbursement. Tables 2 and 3 summarise the reimbursement practice (per activity separately and per

Table 1

Basis of reimbursement and the potential influence of moderately hypofractionated radiation schedules on revenue

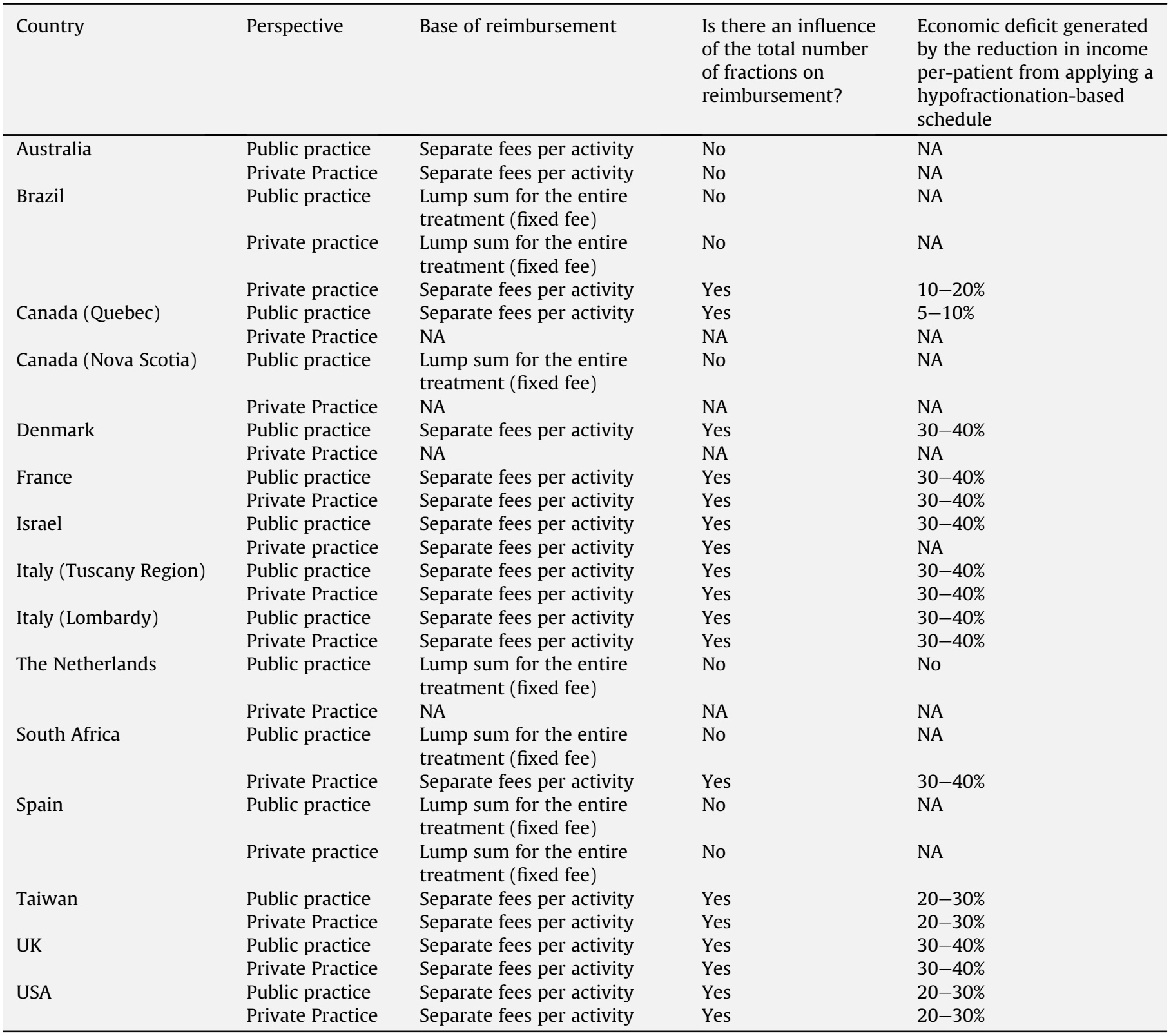

NA, not available. 


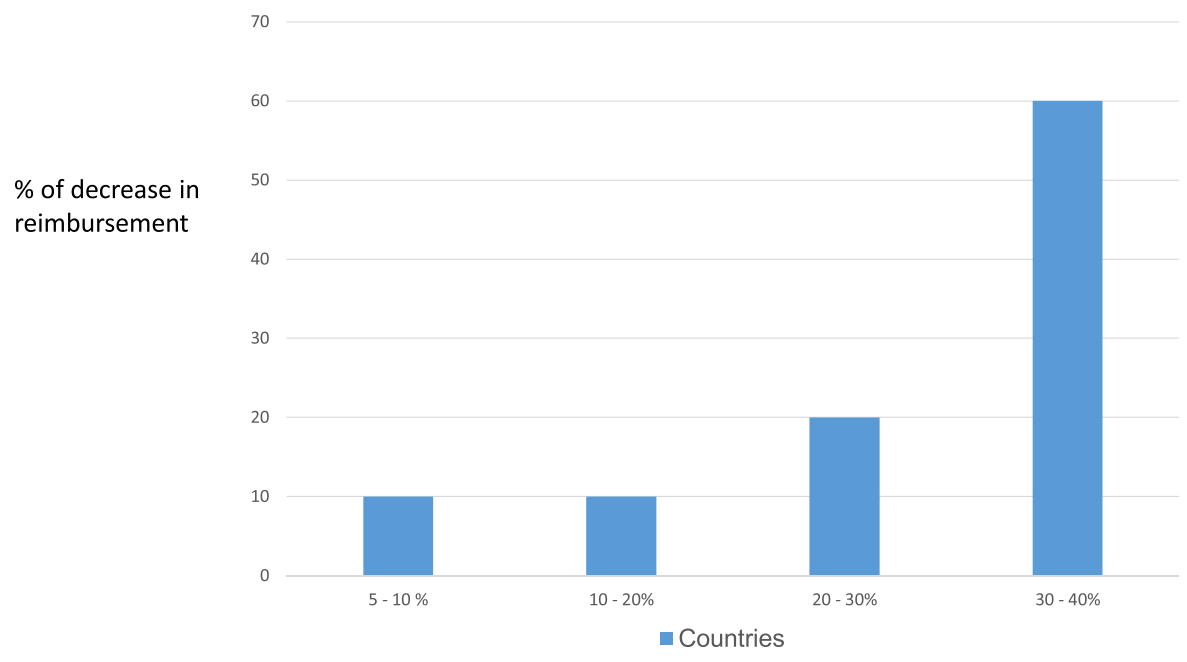

Fig 1. Decrease in remuneration generated by the reduction in per-patient reimbursement from applying a hypofractionation-based schedule compared with conventional fractionation.

lumpsum for the entire treatment) from the public and private perspective, respectively.

\section{Discussion}

To the best of our knowledge, this is the first study reporting the financial impact of worldwide radiation therapy reimbursement systems on the use of moderately hypofractionated postoperative radiation therapy for breast cancer patients. As breast cancer treatment makes up about $25 \%$ of the activities of most radiation oncology departments, a relative financial loss by introducing moderate hypofractionation for breast cancer immediately translates into a major reduction of overall revenues.

In general, a radiation therapy budget is expected to make up just $5 \%$ of yearly cancer care costs and therefore denotes less than $1 \%$ of the total healthcare budget $[3,12]$. To achieve the all-purpose aims of healthcare, there are several methods and tools that can be considered, such as quality, availability, acceptability and accessibility and, based on these, legislation and organisational models are created [13]. The definition of healthcare reimbursement systems involves the concept of the mode by which money is given to the care provider by healthcare customers [14]; suppliers can be institutional (e.g. hospitals), individual (e.g. physicians) or both combined. Although treatment costs and reimbursement are frequently used interchangeably to arrange the background for financial platforms and upcoming assets, it is essential to differentiate reimbursement, which is the consequence of compromises between payers and healthcare suppliers, from costs, which are related to real resource consumption $[15,16]$. The form of reimbursement implemented in a nation provides insight into how the healthcare system offers remuneration for particular treatments [14].

Assessing the costs of radiation therapy is not a simple task and the features and structures available in each country should be considered [16-19]. In the Health
Economics in Radiation Oncology (HERO) - European Society for Radiotherapy and Oncology (ESTRO) study, 52 articles were analysed regarding the type and quality of radiation therapy cost, revealing that cost-calculation studies from the healthcare provider's standpoint still need a robust instrument for measuring radiation therapy costs. The results of methodologically all-encompassing cost studies indicate that the inadequate use of conventional cost-evaluation methods combined with the unsatisfactory data on resource inputs, has hampered comparability across published papers [16].

The cost of radiation therapy is often associated with the necessary investments in infrastructure and high-priced equipment. Radiation therapy equipment capable of more complex treatments such as IMRT require a higher capital expenditure related to both investment and maintenance than those capable of more basic treatments, and this cost is reflected in the higher remuneration to providers for using these techniques. Nevertheless, due to the labour-intensive task of technical planning and radiation therapy treatment delivery, the models of cost estimation show that the costs of salaries noticeably exceed those of equipment $[10,12,20,21]$. When radiation therapy complexity increases, additional costs are incurred to allow for treatment preparation, contemplation of delivery time and quality assurance [22]. It is not surprising, therefore, that radiation therapy costs are also determined by the total treatment period, such that reducing the number of fractions can have a meaningful impact $[3,23]$.

The total cost of radiation therapy includes various components, including the costs of treatment-related activities, hospital overheads and social costs (Figure 2). For breast cancer patients, some cost components are the same for all treatments; for instance, the same radiation therapy technique is generally applied for the entire duration of the treatment regardless of the dose schedule. It is important to highlight that the time freed up can be used to increase the throughput of patients and reduce waiting lists. The time 
Table 2

Public practice. Reimbursement practice - per activity separately and per lump sum for the entire treatment

\begin{tabular}{|c|c|c|c|c|c|c|c|c|c|}
\hline \multirow[t]{2}{*}{ Country } & \multicolumn{6}{|c|}{ Per activity separately } & \multicolumn{3}{|c|}{ Lump sum for the entire treatment } \\
\hline & $\begin{array}{l}2 \mathrm{D} \\
\text { treatment } \\
\text { planning }\end{array}$ & $\begin{array}{l}\text { 3D-CRT } \\
\text { planning }\end{array}$ & $\begin{array}{l}\text { IMRT } \\
\text { planning }\end{array}$ & Per fraction & $\begin{array}{l}\text { Per } \\
\text { treatment } \\
\text { week }\end{array}$ & $\begin{array}{l}\text { For on- } \\
\text { treatment } \\
\text { physician } \\
\text { visits }\end{array}$ & $\begin{array}{l}\text { Whole } \\
\text { treatment } \\
\text { series all- } \\
\text { in }\end{array}$ & $\begin{array}{l}\text { Treatment } \\
\text { series only } \\
\text { radiation } \\
\text { therapy } \\
\text { fractions }\end{array}$ & $\begin{array}{l}\text { Treatment } \\
\text { series } \\
\text { treatment } \\
\text { planning }\end{array}$ \\
\hline $\begin{array}{l}\text { Australia } \\
\text { (dollar) }\end{array}$ & $\begin{array}{l}66.55 \\
-564.15\end{array}$ & $\begin{array}{l}591.65 \\
-1055.30\end{array}$ & 3283.45 & $\begin{array}{l}224.20 \text { (per } \\
\text { IMRT } \\
\text { fraction) }\end{array}$ & $\begin{array}{l}638.50 \\
\text { (simulation) }\end{array}$ & NA & NA & NA & NA \\
\hline Brazil (dollar) & NA & NA & NA & NA & NA & NA & 1512 & NA & NA \\
\hline $\begin{array}{r}\text { Canada - } \\
\text { Quebec } \\
\text { (dollar) }\end{array}$ & NA & 508.75 & 839.8 & NA & 18.15 & 20.15 & NA & NA & NA \\
\hline $\begin{array}{l}\text { Canada - Nova } \\
\text { Scotia } \\
\text { (dollar) }\end{array}$ & 530 & 530 & 530 & 294 & 1470 & 404 & 8070 & 2430 & 530 \\
\hline $\begin{array}{l}\text { Denmark } \\
\text { (euro) }\end{array}$ & NA & 1620 & 1620 & 413 & NA & NA & NA & NA & NA \\
\hline France (euro) & 450 & 1028 & 1128 & $\begin{array}{l}186 \\
395 \\
\text { ('dedicated' } \\
\text { machine) }\end{array}$ & NA & NA & NA & NA & NA \\
\hline Israel (dollar) & NA & 7710 & 21923 & $\begin{array}{l}434 \text { (3D) } \\
1046 \text { (IMRT) }\end{array}$ & $\begin{array}{l}2168 \text { (3D) } \\
5232 \text { (IMRT) }\end{array}$ & NA & NA & NA & NA \\
\hline $\begin{array}{l}\text { Italy - } \\
\text { Tuscany } \\
\text { region (euro) }\end{array}$ & 194 & 608 & 877 & $\begin{array}{l}1500 \text { (HF- } \\
\text { WBI) } 2250 \\
(\mathrm{C}-\mathrm{WBI})\end{array}$ & 375 & 22 (each) & $\begin{array}{l}2108 \text { (HF- } \\
\text { WBI) } \\
2258(C- \\
\text { WBI) }\end{array}$ & $\begin{array}{l}1500(\mathrm{HF}- \\
\text { WBI) } \\
2250(\mathrm{C}- \\
\text { WBI })\end{array}$ & 608 \\
\hline $\begin{array}{l}\text { Italy - } \\
\text { Lombardy } \\
\text { region (euro) }\end{array}$ & 72.85 & 306.60 & 586.52 & $\begin{array}{l}72.52(3 \mathrm{D}) \\
154.32 \\
\text { (IMRT) }\end{array}$ & $\begin{array}{l}362.60(3 \mathrm{D}) \\
771.6 \\
\text { (IMRT) }\end{array}$ & $\begin{array}{l}17.90 \\
\text { (each) }\end{array}$ & 2088 & 1440 & 600 \\
\hline $\begin{array}{l}\text { The } \\
\text { Netherlands } \\
\text { (euro) }\end{array}$ & NA & NA & NA & $\mathrm{NA}$ & NA & NA & NA & $\begin{array}{l}6954.87 \\
10122.34 \\
\text { (with } \\
\text { respiratory } \\
\text { control) }\end{array}$ & 1163.82 \\
\hline $\begin{array}{l}\text { South Africa } \\
\text { (euro) }\end{array}$ & NA & NA & NA & NA & NA & NA & NA & NA & NA \\
\hline Spain (euro) & 861.31 & $\begin{array}{l}2430.20 \\
-3679.16\end{array}$ & 3679.16 & NA & NA & NA & $\begin{array}{l}2430.2 \\
(3 \mathrm{D}) \\
3679.16 \\
(\text { IMRT) }\end{array}$ & NA & NA \\
\hline Taiwan (dollar) & NA & 300 & 600 & 200 & 1000 & 8 & 5000 & 4000 & 1000 \\
\hline UK (pound) & 410.38 & 794.64 & 1383.93 & 158.93 & NA & 100 & NA & NA & NA \\
\hline USA (dollar) & NA & 6150 & 8160 & $\begin{array}{l}226(3 \mathrm{D}) \\
524(\text { IMRT) }\end{array}$ & NA & $\begin{array}{l}199 \text { per } \\
\text { five } \\
\text { fractions }\end{array}$ & NA & NA & NA \\
\hline
\end{tabular}

2D, two dimensional; 3D-CRT, three-dimensional conformal radiation therapy; C-WBI, conventional whole-breast irradiation; HF-WBI, hypofractionated whole-breast irradiation; IMRT, intensity-modulated radiation therapy; NA, not applicable.

made available could be invested in innovative and more time-consuming treatment approaches, including radical treatment for oligometastases. Thereby, the total cost diminishes with a reduction of the number of fractions. From an Australian perspective [24], the financial impact of using hypofractionated post-mastectomy radiation therapy is a cost reduction of over $\$ 2000$ per patient. Similarly, in a US assessment, the per-case marginal reduction of the hypofractionated schedule was $\$ 4297$ for breast cancer patients
[11]. The social-cost perspective should also be part of this discussion. In the US context, Suh et al. [25] estimated the costs of transportation using the average number of miles moved per day, the average reimbursement rate per mile and the parking costs. Using the national average hourly wage for 55- to 64-year-old US women as a reference, the authors calculated the number of hours spent during treatment and displacement. Unsurprisingly, these nondirect medical costs were evidently associated with the 
Table 3

Private practice. Reimbursement practice - per activity separately and per lump sum for the entire treatment

\begin{tabular}{|c|c|c|c|c|c|c|c|c|c|}
\hline \multirow[t]{2}{*}{ Country } & \multicolumn{6}{|c|}{ Per activity separately } & \multicolumn{3}{|c|}{ Lump sum for the entire treatment } \\
\hline & $\begin{array}{l}\text { 2D } \\
\text { treatment } \\
\text { planning }\end{array}$ & $\begin{array}{l}\text { 3D-CRT } \\
\text { planning }\end{array}$ & $\begin{array}{l}\text { IMRT } \\
\text { planning }\end{array}$ & $\begin{array}{l}\text { Per } \\
\text { fraction }\end{array}$ & $\begin{array}{l}\text { Per } \\
\text { treatment } \\
\text { week }\end{array}$ & $\begin{array}{l}\text { For on- } \\
\text { treatment } \\
\text { physician } \\
\text { visits }\end{array}$ & $\begin{array}{l}\text { Whole } \\
\text { treatment } \\
\text { series all-in }\end{array}$ & $\begin{array}{l}\text { Treatment } \\
\text { series only } \\
\text { radiation } \\
\text { therapy } \\
\text { fractions }\end{array}$ & $\begin{array}{l}\text { Treatment } \\
\text { series } \\
\text { treatment } \\
\text { planning }\end{array}$ \\
\hline $\begin{array}{l}\text { Australia } \\
\text { (dollar) }\end{array}$ & $\begin{array}{l}66.55 \\
-564.15\end{array}$ & $\begin{array}{l}591.65 \\
-1055.30\end{array}$ & 3283.45 & $\begin{array}{l}224.20 \\
\text { (per IMRT } \\
\text { fraction) }\end{array}$ & $\begin{array}{l}638.50 \\
\text { (simulation) }\end{array}$ & NA & NA & NA & NA \\
\hline Brazil (dollar) & NA & NA & NA & NA & NA & NA & $\begin{array}{l}5800 \text { (3D) } \\
7572 \text { (IMRT) }\end{array}$ & NA & NA \\
\hline $\begin{array}{l}\text { Canada - } \\
\text { Quebec } \\
\text { (dollar) }\end{array}$ & NA & NA & NA & NA & NA & NA & NA & NA & NA \\
\hline $\begin{array}{l}\text { Canada - Nova } \\
\text { Scotia } \\
\text { (dollar) }\end{array}$ & NA & NA & NA & NA & NA & NA & NA & NA & NA \\
\hline $\begin{array}{l}\text { Denmark } \\
\text { (euro) }\end{array}$ & NA & NA & NA & NA & NA & NA & NA & NA & NA \\
\hline France (euro) & NA & NA & NA & NA & NA & NA & NA & NA & NA \\
\hline Israel (dollar) & NA & NA & NA & NA & NA & NA & NA & NA & NA \\
\hline $\begin{array}{l}\text { Italy - Tuscany } \\
\text { region (euro) }\end{array}$ & 194 & 608 & 877 & $\begin{array}{l}1500 \text { (HF- } \\
\text { WBI) } 2250 \\
\text { (C-WBI) }\end{array}$ & 375 & 22 (each) & $\begin{array}{l}2108 \text { (HF- } \\
\text { WBI) } \\
2258(C- \\
\text { WBI) }\end{array}$ & $\begin{array}{l}1500 \text { (HF- } \\
\text { WBI) } \\
2250 \text { (C- } \\
\text { WBI) }\end{array}$ & 608 \\
\hline $\begin{array}{l}\text { Italy - } \\
\text { Lombardy } \\
\text { region (euro) }\end{array}$ & 94.71 & 398.58 & 763.78 & $\begin{array}{l}94.33(3 \mathrm{D}) \\
200.62 \\
\text { (IMRT) }\end{array}$ & $\begin{array}{l}471.65(3 \mathrm{D}) \\
1003.1 \\
(\text { IMRT) }\end{array}$ & $\begin{array}{l}23.27 \\
\text { (each) }\end{array}$ & 2610 & 1800 & 810 \\
\hline $\begin{array}{l}\text { The } \\
\text { Netherlands } \\
\text { (euro) }\end{array}$ & NA & NA & NA & NA & NA & NA & NA & NA & NA \\
\hline $\begin{array}{l}\text { South Africa } \\
\text { (euro) }\end{array}$ & 588 & 1265 & 2700 & 474 & 814 & 0 & NA & NA & NA \\
\hline Spain (euro) & 1500 & $\begin{array}{l}1500 \\
-3600\end{array}$ & 5500 & NA & NA & NA & $\begin{array}{l}1500-3600 \\
(3 \mathrm{D}) \\
5500 \text { (IMRT) }\end{array}$ & NA & NA \\
\hline Taiwan (dollar) & NA & 300 & 600 & 200 & 1000 & 8 & 5000 & 4000 & 1000 \\
\hline UK (pound) & 2400 & 2700 & 3635 & 550 & NA & NA & NA & NA & NA \\
\hline USA (dollar) & NA & $\begin{array}{l}7380 \\
-9225\end{array}$ & $\begin{array}{l}9792 \\
-12240\end{array}$ & $\begin{array}{l}271-339 \\
(3 \mathrm{D}) \\
629-786 \\
(\text { IMRT) }\end{array}$ & NA & $\begin{array}{l}239-298 \\
\text { per five } \\
\text { fractions }\end{array}$ & NA & NA & NA \\
\hline
\end{tabular}

2D, two dimensional; 3D-CRT, three-dimensional conformal radiation therapy; C-WBI, conventional whole-breast irradiation; HF-WBI, hypofractionated whole-breast irradiation; IMRT, intensity-modulated radiation therapy; NA, not applicable.

total treatment period (i.e. the number of fractions) and shorter total treatment times were advantageous [25]. A study from Ontario, which has a socialised healthcare system, showed that for whole-breast irradiation, patients were bearing $37 \%$ of the treatment cost because of the daily commute to the hospital [26].

In addition to the evident benefit of hypofractionation on costs [3,27], it is important to review the reimbursement system in an overall evaluation of institutions before adopting shorter schedules as practice. Konski et al. [11] showed the consequences in terms of costs and reimbursement when a US radiation oncology department used hypofractionation for most common tumours, thus exploiting Medicaid- and Medicare-qualified unit values and reimbursement rates. The relative value unit for 2015 was used to establish any alterations in reimbursements. The variation in the total number of fractions was adjusted to measure the consequences in terms of staff time, machine capacity and workforce predictions. The results indicated that if 100 breast cancer patients are treated with shorter schedules, hospital-based technical billing due to hypofractionation would be reduced by $\$ 429$ 699.98. The per-case marginal reduction for each physician was 10.44 relative value units, representing a decrease of 1044 relative value units for each 100 breast cancer patients who receive hypofractionation. Hence, considering these US-based cost calculations, an increase in hypofractionation prescription over conventional fractionation 


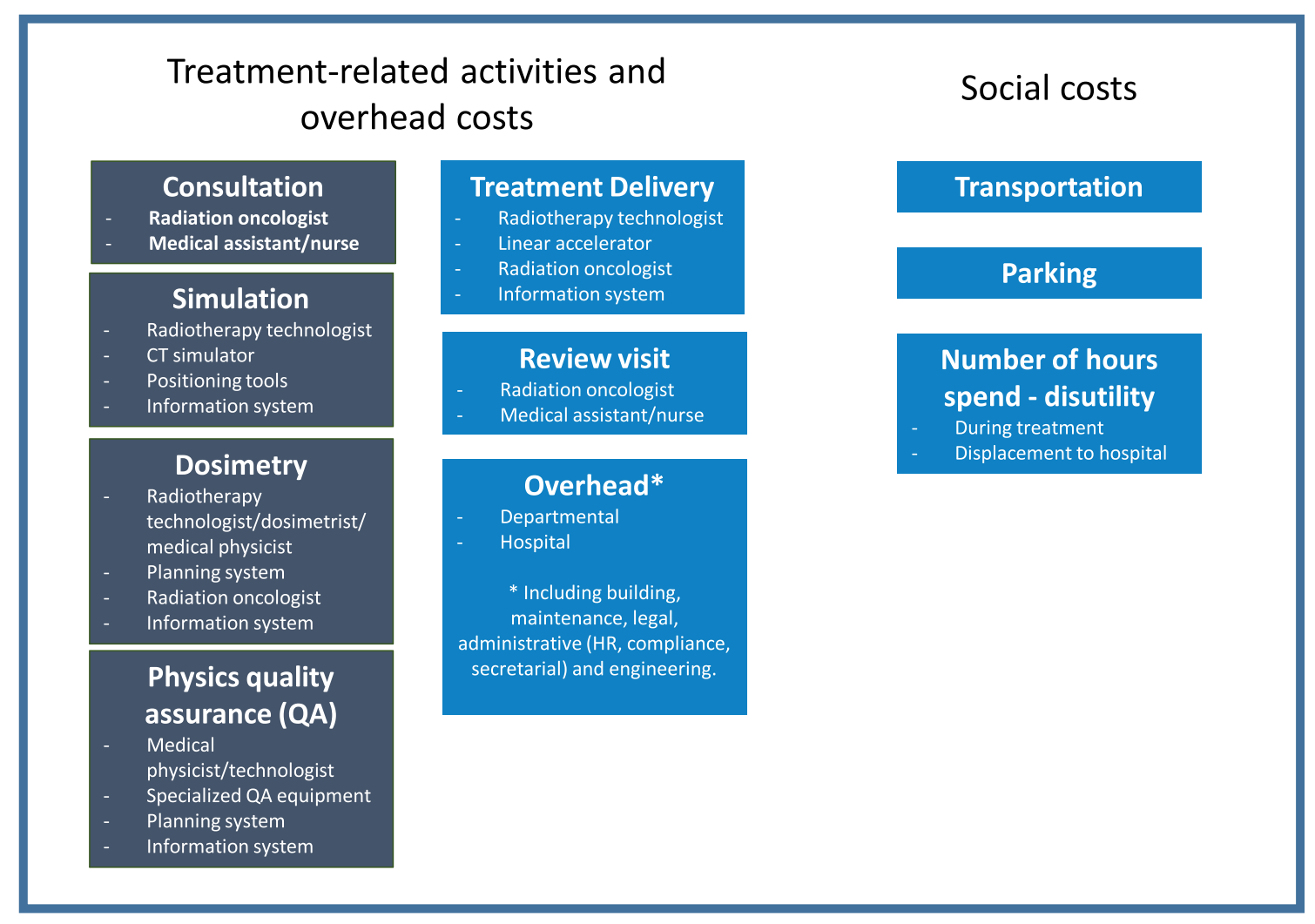

Fig 2. Costs of treatment-related activities, hospital overheads and social costs.

will decrease the demand on radiation oncology departments, which will then have to deal, at least on the short to intermediate term, with financial losses resulting from a reduction in per-patient income in fractionationbased reimbursement arrangements.

This study shows that although reimbursement practices differ across public and private institutions and between countries, the financial loss from a reduction in per-patient income due to the use of a hypofractionation-based schedule is substantial and quite similar across payment systems and countries (Table 2, Figure 1). It is important to highlight that the reimbursement information was provided by the authors of this study. Although there may be even more variation when also taking not-evaluated medical services into account, the retrieved data serve as the basis for an overview of reimbursement amounts for each country across public and private practices in Europe, the Americas, Africa, Asia and Oceania. Moreover, the results of this study are in agreement with a recent report from the HERO-ESTRO group that analysed the reimbursement of public health radiation therapy services in Europe [15]. Moreover, as illustrated in Tables 2 and 3, reimbursement is not only based on the number of fractions but also on the complexity of the technique used, wherein complex treatment planning is generally associated with higher reimbursement fees.

Reimbursement of treatment planning and treatment delivery may depend on a number of other factors that vary between countries: complexity of delivery, image guidance, respiratory control, etc. The introduction of new techniques and/or modalities in radiation oncology is most often translated into the 'level of complexity'. With fractionation being the main factor in most fee-for-service systems and other co-variables adding up to a huge number of possible combinations, we focused solely on the effect of hypofractionation. Healthcare reimbursement is adapted, depending on the country, at intervals varying between annually up to exceeding a decade.

The objective to provide reliable, safe and high-quality radiation therapy while minimising both acute and late side-effects is related to optimal treatment planning and delivery, independent of the fractionation schedule used. By contrast, the antiquated system of paying by fraction number is nonsensical and counterintuitive, hampering the introduction of evidence-based shorter therapy schedules. Very recently, the first tumour outcome-related end point evaluation from the FAST Forward trial was published $[28,29]$, which proposed a schedule of just five fractions in 1 week. If a mod If a moderately hypofractionated schedule is replaced for many patients in the coming years by a 5 fractions in 1 week schedule, it will demand much more robustness of RT treatment planning and delivery. These few fractions could hence cost more per fraction (due to the more complex verification) than conventional fractionation and moderate hypofractionation to plan and deliver. Thus, it is important to propose a better remuneration system based on complexity rather than one so heavily influenced by fraction number. 
The best solution to this impasse is probably to introduce improved and optimised reimbursement and healthcare delivery systems. Recently, scholars worldwide have examined various delivery and payment models, including those that are evolutions of the fee-for-service system [30]. Optimal alternative payment systems aim at enhancing clinical outcomes and decreasing both consumption and costs. To maximise outcomes, the model (value-based) intervention ought to be focused on improving the equilibrium between cost and healthcare quality. The value-based payment concept - in which healthcare consumers and payers maintain the distribution system that is largely responsible for both costs and quality of care - is one of the most studied models, and it promises to have a positive impact in this framework. However, it is important to recognise that, notwithstanding the advances of alternative payment systems, there is still limited evidence regarding the efficacy of these reimbursement models; this issue requires further debate before practical implementation [31,32].

The financial discussion of the viability of widespread adoption of moderate hypofractionation in breast cancer patients has special importance for countries with limited resources [33-35]. Khan et al. [36] evaluated the impact of shorter schedules for breast cancer patients from countries with emerging economies and restricted radiation therapy assets. The implementation of hypofractionation in these emerging economies is not merely an issue of increased cost-effectiveness but also one of improved access to quality healthcare and enhanced patient survivorship. A shift from a conventional schedule to hypofractionation could thereby decrease waiting times and allow more patients to be treated, particularly in systems with restricted funds [37,38].

Finally, the importance of hypofractionation has perhaps never before been clearer than in the current pandemic. The reduction in the number of patient visits to the radiation oncology department by using hypofractionation is particularly important, insofar as this approach limits the risk for disease transmission for both patients and personnel, while at the same time preventing jeopardising the outcomes of cancer intervention [39,40]. Although our study was conducted before the worldwide COVID-19 pandemic, its insights are even more relevant now and for the future. Finally, it is unethical to deny any patient access to evidenced-based moderate breast hypofractionation based on a potential loss of income. Out-dated reimbursement systems need to be re-designed to facilitate implementation of high-quality randomised trial results and reflect complex and quality-assured modern radiation therapy.

\section{Conclusions}

Moderately hypofractionated radiation therapy schedules are preferable for breast cancer patients, by decreasing the daily burden linked to travel and disutility following a lower number of treatment fractions, but similar rates of local relapse and often reduced side-effects. Moreover, its widespread adoption will also be beneficial for healthcare systems, by reducing the workload for both healthcare providers and infrastructure, especially when resources are limited. The possible financial loss induced by the reduction in per-patient income due to fractionation-based reimbursement should be compensated by an evolution of the reimbursement model from a fee-for-service system to a bundled payment system. In this context, the reimbursement systems should be more adaptable based on progress in both knowledge and techniques, and not remain so inert over time. We therefore favour a change in the current fee-for-service model prevalent worldwide, to one which allows for better compensation for increased quality in treatment planning and delivery. The reimbursement amount could then be based on average cost data collected from patients receiving optimal breast radiation therapy. As reimbursement in such a model should be independent of the type of radiation therapy planning and the number of fractions, clinicians may be more inclined to favour moderately hypofractionated treatment schedules and their associated radiation therapy planning. This would improve value for all stakeholders, including doctors, payers and the country's healthcare system, but above all improve the patient experience, which is paramount.

\section{Conflicts of interest}

The authors declare no conflict of interest.

\section{Funding}

This research did not receive any specific grant from funding agencies in the public, commercial or not-for-profit sectors.

\section{Acknowledgement}

The authors thank L. Triggiani (University of Brescia, Italy) for providing the data from Italy (Lombardy Region).

\section{References}

[1] Siegel RL, Miller KD, Jemal A. Cancer statistics. CA Cancer J Clin 2019;69:7-34.

[2] Luengo-Fernandez R, Leal J, Gray A, Sullivan R. Economic burden of cancer across the European Union: a populationbased cost analysis. Lancet Oncol 2013;14:1165-1174.

[3] Lievens Y. Hypofractionated breast radiotherapy: financial and economic consequences. Breast 2010;19:192-197.

[4] Early Breast Cancer Trialists' Collaborative GroupDarby S, McGale P, Correa C, Taylor C, Arriagada R, Clarke M, et al. Effect of radiotherapy after breast-conserving surgery on 10-year recurrence and 15-year breast cancer death: meta-analysis of individual patient data for 10,801 women in 17 randomised trials. Lancet 2011;378:1707-1716.

[5] Early Breast Cancer Trialists' Collaborative GroupMcGale P, Taylor C, Correa C, Cutter D, Duane F, Ewertz M, et al. Effect of radiotherapy after mastectomy and axillary surgery on 10year recurrence and 20-year breast cancer mortality: metaanalysis of individual patient data for 8135 women in 22 randomised trials. Lancet 2014;383:2127-2135. 
[6] Whelan T, MacKenzie R, Julian J, Levine M, Shelley W, Grimard L, et al. Randomized trial of breast irradiation schedules after lumpectomy for women with lymph nodenegative breast cancer. J Natl Cancer Inst 2002;94:1143-1150.

[7] Yarnold J, Ashton A, Bliss J, Homewood J, Harper C, Hanson J, et al. Fractionation sensitivity and dose response of late adverse effects in the breast after radiotherapy for early breast cancer: long-term results of a randomised trial. Radiother Oncol 2005;75:9-17.

[8] Valle LF, Agarwal S, Bickel KE, Herchek HA, Nalepinski DC, Kapadia NS. Hypofractionated whole breast radiotherapy in breast conservation for early-stage breast cancer: a systematic review and meta-analysis of randomized trials. Breast Cancer Res Treat 2017;162:409-417.

[9] Marta GN, Coles C, Kaidar-Person O, Meattini I, Hijal T, Zissiadis Y, et al. The use of moderately hypofractionated postoperative radiation therapy for breast cancer in clinical practice: a critical review. Crit Rev Oncol Hematol 2020;156:103090.

[10] Lievens Y, van den Bogaert W, Kesteloot K. Activity-based costing: a practical model for cost calculation in radiotherapy. Int J Radiat Oncol Biol Phys 2003;57:522-535.

[11] Konski A, Yu JB, Freedman G, Harrison LB, Johnstone PA. Radiation oncology practice: adjusting to a new reimbursement model. J Oncol Pract 2016;12:e576-e583.

[12] Norlund A, Group SBUS. Costs of radiotherapy. Acta Oncol 2003;42:411-415.

[13] Slotman BJ, Cottier B, Bentzen SM, Heeren G, Lievens Y, van den Bogaert W. Overview of national guidelines for infrastructure and staffing of radiotherapy. ESTRO-QUARTS: work package 1. Radiother Oncol 2005;75:349-354.

[14] Jegers M, Kesteloot K, De Graeve D, Gilles W. A typology for provider payment systems in health care. Health Policy 2002; 60:255-273.

[15] Lievens Y, Defourny N, Corral J, Gasparotto C, Grau C, Borras JM, et al. How public health services pay for radiotherapy in Europe: an ESTRO-HERO analysis of reimbursement. Lancet Oncol 2020;21:e42-e54.

[16] Defourny N, Dunscombe P, Perrier L, Grau C, Lievens Y. Cost evaluations of radiotherapy: what do we know? An ESTROHERO analysis. Radiother Oncol 2016;121:468-474.

[17] Zubizarreta E, Van Dyk J, Lievens Y. Analysis of global radiotherapy needs and costs by geographic region and income level. Clin Oncol 2017;29:84-92.

[18] Van Dyk J, Zubizarreta E, Lievens Y. Cost evaluation to optimise radiation therapy implementation in different income settings: a time-driven activity-based analysis. Radiother Oncol 2017;125:178-185.

[19] Atun R, Jaffray DA, Barton MB, Bray F, Baumann M, Vikram B, et al. Expanding global access to radiotherapy. Lancet Oncol 2015;16:1153-1186.

[20] Perez CA, Kobeissi B, Smith BD, Fox S, Grigsby PW, Purdy JA, et al. Cost accounting in radiation oncology: a computerbased model for reimbursement. Int J Radiat Oncol Biol Phys 1993;25:895-906.

[21] Ploquin NP, Dunscombe PB. The cost of radiation therapy. Radiother Oncol 2008;86:217-223.

[22] Van de Werf E, Lievens Y, Verstraete J, Pauwels K, Van den Bogaert $\mathrm{W}$. Time and motion study of radiotherapy delivery: economic burden of increased quality assurance and IMRT. Radiother Oncol 2009;93:137-140.

[23] Defourny N, Perrier L, Borras JM, Coffey M, Corral J, Hoozee S, et al. National costs and resource requirements of external beam radiotherapy: a time-driven activity-based costing model from the ESTRO-HERO project. Radiother Oncol 2019; 138:187-194.
[24] Mortimer JW, McLachlan CS, Hansen CJ, Assareh H, Last A, McKay MJ, et al. Use of hypofractionated post-mastectomy radiotherapy reduces health costs by over $\$ 2000$ per patient: an Australian perspective. J Med Imaging Radiat Oncol 2016;60:146-153.

[25] Suh WW, Pierce LJ, Vicini FA, Hayman JA. A cost comparison analysis of partial versus whole-breast irradiation after breast-conserving surgery for early-stage breast cancer. Int J Radiat Oncol Biol Phys 2005;62:790-796.

[26] McGuffin M, Merino T, Keller B, Pignol JP. Who should bear the cost of convenience? A cost-effectiveness analysis comparing external beam and brachytherapy radiotherapy techniques for early stage breast cancer. Clin Oncol 2017;29:e57-e63.

[27] Bekelman JE, Sylwestrzak G, Barron J, Liu J, Epstein AJ, Freedman G, et al. Uptake and costs of hypofractionated vs conventional whole breast irradiation after breast conserving surgery in the United States, 2008-2013. JAMA 2014;312: 2542-2550.

[28] Brunt AM, Wheatley D, Yarnold J, Somaiah N, Kelly S, Harnett A, et al. Acute skin toxicity associated with a 1-week schedule of whole breast radiotherapy compared with a standard 3-week regimen delivered in the UK FAST-Forward Trial. Radiother Oncol 2016;120:114-118.

[29] Brunt AM, Haviland JS, Wheatley AD, Sydenham MA, Alhasso A, Bloomfield DJ, et al. Hypofractionated breast radiotherapy for 1 week versus 3 weeks (FAST-Forward): 5year efficacy and late normal tissue effects results from a multicentre, non-inferiority, randomised, phase 3 trial. Lancet Oncol 2020;395:1613-1626. https://doi.org/10.1016/S01406736(20)30932-6.

[30] Conrad DA. The theory of value-based payment incentives and their application to health care. Health Serv Res 2015; 50(Suppl. 2):2057-2089.

[31] Aviki EM, Schleicher SM, Mullangi S, Matsoukas K, Korenstein D. Alternative payment and care-delivery models in oncology: a systematic review. Cancer 2018;124:3293-3306.

[32] Porter ME. What is value in health care? N Engl J Med 2010; 363:2477-2481.

[33] Ash DV. Waiting times for cancer treatment. Clin Oncol 2000; 12:140.

[34] Mackillop WJ, Fu H, Quirt CF, Dixon P, Brundage M, Zhou Y. Waiting for radiotherapy in Ontario. Int J Radiat Oncol Biol Phys 1994;30:221-228.

[35] Moraes FY, Mendez LC, Rosa AA, Marta GN. Expanding access to radiation therapy: an update on Brazil's current challenges and opportunities. Int J Radiat Oncol Biol Phys 2018;102:463-464.

[36] Khan AJ, Rafique R, Zafar W, Shah C, Haffty BG, Vicini F, et al. Nation-scale adoption of shorter breast radiation therapy schedules can increase survival in resource constrained economies: results from a Markov Chain analysis. Int J Radiat Oncol Biol Phys 2017;97:287-295.

[37] Dwyer P, Hickey B, Burmeister E, Burmeister B. Hypofractionated whole-breast radiotherapy: impact on departmental waiting times and cost. J Med Imaging Radiat Oncol 2010;54: 229-234.

[38] Bhattacharyya T, Mahajan R, Ghoshal S, Yadav BS, Rai B. Hypofractionated radiotherapy in carcinoma breast: what we have achieved? J Cancer Res Ther 2015;11:259-263.

[39] Coles CE, Aristei C, Bliss J, Boersma L, Brunt AM, Chatterjee S, et al. International guidelines on radiation therapy for breast cancer during the COVID-19 pandemic. Clin Oncol 2020;32:279-281.

[40] Curigliano G, Cardoso MJ, Poortmans P, Gentilini O, Pravettoni G, Mazzocco K, et al. Recommendations for triage, prioritization and treatment of breast cancer patients during the COVID-19 pandemic. Breast 2020;52:8-16. 